\title{
Beyond rhetoric: reinventing the public mission of higher education
}

\section{Antigoni Papadimitriou ${ }^{1}$}

Received: 18 June 2019 / Accepted: 26 July 2019 /Published online: 3 August 2019

(C) The European Higher Education Society 2019

The concept of the "public mission" of higher education institutions has several dimensions. In the broader and more general sense, it is the institution's public mission to provide knowledge, critical reflection and discourse on the larger and more fundamental questions of society. This general function has become recently challenged as some governments openly question or simply dismiss scientific evidence. The discussion of this more fundamental dimension of "society engagement" is therefore very timely. The second meaning, "community engagement", emphasizes the more instrumental dimension: collaboration of various kinds between higher education institutions and their "communities".

To many universities and other higher education institutions are attributed three major, interrelated missions: education, the generation of new knowledge, and engagement with society or "the community". While the processes and structures associated with teaching and research are relatively well defined and analyzed, this is less the case with the public mission. Mission statements, websites and promotional materials often underline an institution's commitment to community engagement and public responsibility. However, despite the growing importance of higher education's public mission at a declamatory level, its implementation in practice is not clear-cut. The wide range of activity incorporated in universities and colleges' community engagement suggests that a precise definition of the public mission is difficult, and that organizing and coordinating such external activities and internal policies and practices is a complex task.

This task might begin with articulating, generally, the current and future public mission of higher education, and what difference this mission makes to society and the community as well as to the higher education institutions. Another question is which specific public missions apply to which universities and higher education institutions? This will depend on their respective internal characteristics (e.g. traditions, mission, structures and policies), external environment (e.g., demographics, sociocultural, economic and political), and the variety of the institution's stakeholders, both internal and external.

Antigoni Papadimitriou apapadi1@jhu.edu 
Looking to the future, higher education institutions will have to become or remain active to move with the political, economic and technological winds. With increased globalization, many institutions will have to reimagine themselves in the light of global citizenship. Many institutions will rely increasingly upon online delivery education. Public mission will need to be well-defined, well-planned and well-supported. The means of assessment will need to be clear, relevant and effective.

This special issue invited contributions dealing with the theme of the public mission of higher education. The goal was to provide an understanding of the issues related to public mission in higher education and to explore and promote new solutions at national and international levels.

Oravec argues that community engagement has played a central role in tertiary education, expanding the potentials for academic as well as civic enhancement. Such efforts are often undertaken in part with the use of metrics, as tertiary education institutions attempt to reach various community audiences with quantitatively-supported defenses of their missions, through research analyses and publications, and with their participation in formal institutional ranking systems. However, dramatic expansions of the use of metrics and the importance of publications for academics have fostered gaming and manipulation practices designed to enhance artificially both individual and institutional reputations, including predatory journal administration, coercive citation, forced joint authorship, paper mill and ghostwriting efforts, H-index manipulation, creation of bogus documents, development of fraudulent academic conferences and many others, as well as falsified research itself. As they emerge in the press or in watchdog reports, such questionable practices can disturb delicate negotiations concerning the respective roles of communities and academic institutions as well as be perceived by some community members as violations of trust. The practices can be especially harmful when associated with celebrity or "star" academics who often are granted substantial institutional leeway. Her study maps an assortment of these emerging practices from a community engagement perspective; the study also analyzes recent discourse as to the impacts which the normalization of these practices are having on community-academic interactions. Oravec discusses strategies toward making production and use of academic metrics and related research output less easily manipulated and more worthy of trust both by academic participants and the community as a whole.

Serna, relying on a multitude of studies from the college choice literature, proposes an updated model of college going and choice that draws on four conceptual, theoretical and analytic approaches. With guidance from the economic, sociological, information processing and combined theories of college choice, the author situates his proposed framework within this extant literature to provide some direction and formal conceptualization of the role that signalling and identity play with regard to college access. In addition to understanding students' identities within typical utility models, this essay also attempts to carefully consider both the explicit and implicit assumptions about valued identity categories (insiders) and those that are less valued (outsiders) in the college going and choice process. Finally, through deliberate examination of how signals are sent to students and the acquisition of signals (credentials) by students, Serna considered how this relays information about which identities are valued by higher education socially, and by specific institutions in particular. In so doing, he has laid a foundation for future work that carefully ties philosophical and public good notions back to the college choice process and to higher education's underlying ethos of service in the public interest. 
Borkoski and Prosser examined a US Research 1 (research intensive) university faculty's perception of community engagement in the form of service-learning, and implemented an online community of practice for faculty and community members to increase the faculty's use of service learning. The findings revealed that, although faculty see many benefits in implementing service-learning and report interest in learning about and using this pedagogy, service-learning practices are still considered an addition to faculty workloads rather than an integrated and expected role. The faculty reported concerns about the mixed messages within the institution around the value of their investment in this practice, including the lack of recognition in promotion and their feelings around professional obligations particularly related to research publications. Although faculty described teaching as equally important to research, they also perceived that the institution valued teaching and service as less important than research. This research provides further evidence that community engagement activities need to be embedded in faculty roles and rewards to become institutionalized. Implications for practice and research are also discussed.

Berghaeuser and Hoelscher discuss the third mission of higher education in Germany. Higher education systems are changing due to trends of funding pressures, increasing social demands and growing numbers of students. Even though teaching and research are still considered as the pivotal functions of universities, other activities such as technology transfer, lifelong learning or social engagement have broadened the scope of their actions. These activities, labelled as third mission, are supposed to strengthen the impact of science in society and epitomize the changing role of universities. In Germany, the federal government and the states announced different programs aiming to foster these activities, e.g. the "Innovative Hochschule" or Real-world Laboratories. In this article, the authors first develop a definition framework of the third mission. In two further steps they analyze how politics and policies in Germany have framed the concept in the last few years and how public universities are responding to this in their formal structure. They use neo-institutional theory, according to which organizations such as universities create institutionalized structures and reflect institutional rules in order to maintain legitimacy. As an example of organizational formal structure the authors analyzed mission statements of public universities. Using computer-based qualitative content analysis, they assess to what extent these universities take up the third mission. Their results show that most universities mention the third mission in their mission statements. However, the focus is mainly limited to economic impact and (technical) knowledge transfer. Much less emphasis is put on civic engagement or further education issues.

Egorov, Leshukov and Froumin explore the incentive factors that serve to instigate university engagement in the third-mission agenda based on evidence drawn from the Russian system of higher education. They pay special attention to how the split of natural and externally induced drivers of the third mission has changed from the Soviet era. Their analysis has shown that the balance of these two types of incentives never remained flat over the course of history as the Russian university system encountered and had to address different challenges and imperatives at various points in time. The authors have also found that, while federal initiatives have been adopted by the Russian state that have created a distinctive cohort of universities entrusted with comprehensively contributing to the socio-economic and innovative potential of their host localities as a top-priority task, the third-mission agenda is by no means reduced solely to this very group of institutions, as there are many other universities that are not directly expected to focus on the third mission, but which still favor pursuing proactive and fruitful collaborations with regional stakeholders as arguably representing one of the crucial factors in long-term university sustainability. 
Andreadakis's study relyies upon the heuristic presuppositions of behavioral economics analysis, in order to offer an expanded analysis of the public mission mandate of the Greek higher education sector. The examination outlines and parses qualitative evidence issued from the Greek Ministry of Education, and in particular from the hitherto untranslated document A Strategy for Higher Education in Greece: 2016-2020, in conjunction with a growing body of scholarship on the challenges of cultivating public trust in the Greek social landscape. The discussion negotiates the position of the Greek higher education system as a system of sustainable social prosperity and argues that its operational conditions of financial scarcity may entail broader and inadvertent ramifications, namely, the depletion of cognitive resources and the propagation of narrow mental frames in the pursuit of a public mission.

Shawa argues that community engagement as a public mission of higher education is widely accepted in South Africa. This is articulated in White Paper 3 on the transformation of higher education and in institutional policies that promote different forms of community engagement. However, compared to the traditional roles of teaching and research, community engagement remains contested. It is most often viewed as voluntary and perhaps even peripheral. Given the serious social disparities in South Africa, community engagement needs to be invigorated and placed on par with the teaching and researching roles of universities. Furthermore, it should not only involve collaborative knowledge production, but should combine epistemological and ontological dimensions and involve holistic human development capable of dealing with social disparities. A combined epistemological-ontological conception of community engagement is developed in this study and interventions are proposed at three levels. First, university induction programs, which tend to prioritize the teaching and researching roles of faculty members, should consider community engagement as equally important. Second, just as the teaching and researching roles tend to be well planned and/or incentivized, so too should community engagement. Third, community engagement should adopt a mode 2 knowledge production lens where community members reflexively produce knowledge together with faculty members and contribute to holistic human development. Finally, strategies are suggested to embed an epistemological-ontological conception of community engagement.

Ndibuuza's contribution is based on a study conducted to establish if academic practice in a university designated as Azania is aligning or diverting from the expectations of the rising knowledge society in South Africa. The study is motivated by the emerging national needs specific to the production, dissemination and application of knowledge as the country takes steps towards knowledge led development. The general assumption is that academic practice in universities is spontaneously responding to the needs of its changing environment. Thus, to establish the position of academic practice in Azania, institutional and national documents were examined from a neo-institutional perspective through qualitative discourse analysis. The results showed that research, teaching and outreach at the university were responding to national needs. Thus, academic practice in Azania is aligning more than diverting from the expectations of the rising knowledge society.

Pulisher's note Springer Nature remains neutral with regard to jurisdictional claims in published maps and institutional affiliations 